\title{
Empresas de inserción vascas: una herramienta eficaz y eficiente para la inclusión sociolaboral
}

\author{
Leire Álvarez de Eulate Bada \\ Gizatea-Asociación de Empresas de Inserción del País Vasco \\ <gizatea@gizatea.net>
}

\begin{abstract}
Gizarteratzeko enpresen inguruko artikulu honetan, jatorriaren testuingurua zehaztu eta laburki indarrean dagoen legedia berrikusi ondoren, deskribatzen da Euskal Autonomia Erkidegoan izandako garapena, eta eskaintzen dira oinarrizko datu ekonomiko eta sozialak, berauen bidez erakusteko krisialdiko urterik gogorrenetan ere, bazterkeria arrisku edo egoeran dauden biztanleak gizarteratu eta laneko munduan txertatzeko ekimen hauek duten eraginkortasun eta efizientzia. Horren ondoren, aztertzen dira sustapen eta promoziorako indarrean dauden neurriak, eta nabarmentzen da interes ekonomiko orokorreko zerbitzu-emaile eta kontratu berezien onuradun gisara estatu-eskala batean duten onespena. Azkenik, adierazten da zeintzuk diren egungo eta etorkizuneko erronkak, eta horiek zehaztu ziren 2016 eta 2017. Urteetan Gizatea, Gizarteratzeko eta Laneratzeko Euskadiko Enpresen Elkarteak buruturiko hausnarketa prozesu batean.
\end{abstract}

\section{GAKO-HITZAK:}

Gizarteratzeko enpresak, gizarte eta lan-txertaketa, gizarteratzea, interes ekonomiko orokorreko erakundeak, kontratu bereziak, gizarte-klausulak.
El presente artículo sobre las empresas de inserción, tras contextualizar su origen y repasar brevemente la legislación de referencia en vigor, describe su desarrollo en el ámbito de la Comunidad Autónoma Vasca, apuntando sus principales datos económicos y sociales, que ponen de manifiesto la eficacia y eficiencia de estas iniciativas en la inclusión sociolaboral de personas en situación o riesgo de exclusión social, eficacia y eficiencia demostradas incluso en los años más duros de la crisis. Se analizan a continuación las medidas vigentes para su fomento y promoción, destacándose su reconocimiento a escala estatal como entidades prestadoras de servicios de interés económico general y como beneficiarias de contratos reservados. Finalmente, se apuntan los principales retos presentes y futuros, identificados durante 2016 y 2017 en un proceso de reflexión impulsado por Gizatea, la Asociación de Empresas de Inserción del País Vasco.

\section{Palabras Clave:}

Empresas de inserción, inserción sociolaboral, inclusión social, entidades prestadoras de servicios de interés económico general, contratos reservados, cláusulas sociales. 


\section{Origen de las empresas de inserción}

Las empresas de inserción tienen su origen, en el contexto del Estado español, en iniciativas de intervención social, de carácter no lucrativo, especializadas en el ámbito de la inserción social y laboral de personas en situación o riesgo de exclusión social. Estas entidades, que venían trabajando en el ámbito de la formación - prelaboral, ocupacional y laboral, formal y no formal, educativa y profesional-, así como en el de la intermediación laboral -orientación y búsqueda de empleo-, consideraron la posibilidad de abrir una nueva vía de trabajo intermedia entre ambas estrategias. Esta reflexión fue desarrollándose en los años ochenta y dio impulso a la creación de algunas estructuras socioeconómicas que anticiparon a las ya denominadas empresas de inserción en los años noventa.

Esta vía (Askunze, 2016) podría resumirse en algunas reflexiones e intuiciones originadas en su propia experiencia de éxitos y fracasos en el ámbito de la inserción sociolaboral:

- Existe un consenso social generalizado en considerar el desempleo como un grave problema que tiene como consecuencia directa la exclusión económica de las personas, que, en muchos casos, o bien acarrea o bien se combina con otras dificultades de participación e inclusión social, como el acceso a la vivienda, la salud, las redes relacionales o el ejercicio de los derechos de ciudadanía.

- Desde esta perspectiva, se considera, consecuentemente, que el empleo es un elemento central en las estrategias de incorporación e inclusión social, en cuanto proveedor de ingresos para las personas, lo que les permite ejercitar sus derechos y participar en las dinámicas sociales, culturales o políticas. Además, esta estrategia se presenta como preferente en la vía de socialización en el modelo de vida de nuestras sociedades, dada la centralidad que el empleo ocupa, no sólo como proveedor de recursos económicos, sino también como un eje articulador central, en buena medida, de los proyectos vitales de las personas ${ }^{1}$.

- Sin embargo, ni todas las personas se encuentran en desempleo por las mismas causas, ni éste afecta a todas por igual. Así, quienes vienen trabajando con sectores de población que tienen especiales dificultades de acceso al empleo por diferentes motivos (exclusión social y económica,

${ }^{1}$ Si bien hoy el empleo continúa jugando un papel central en los procesos de cohesión social, se ha abierto un debate sobre su función en el futuro, que podría resumirse en la idea de que el empleo no siempre garantiza la inclusión social (existen cada vez más personas con empleo en situación de precariedad o exclusión -habiéndose incluso acuñado el término de 'trabajadoras pobres'- y el acceso al empleo es cada vez menos universal). Un empleo decente sigue siendo una buena herramienta para dicha estrategia inclusiva, pero ello no impide que se deba reflexionar y abordar este debate, también en el seno de las empresas de inserción. baja cualificación, desconexión social, problemas de salud, habilidades sociales y relaciones limitadas), reclaman la necesidad de diversificar y personalizar las diferentes estrategias e instrumentos de inserción laboral.

- Desde esta perspectiva, se identifica un perfil de personas desempleadas para quienes la formación para la mejora de su empleabilidad no es condición suficiente para el acceso más o menos normalizado al mercado laboral. Por decirlo de una forma sencilla, no son personas en las mejores condiciones para acceder a un puesto de trabajo - caso de que exista esa oportunidadaun habiendo agotado las diversas opciones formativas para el empleo.

Partiendo de estas consideraciones y pensando en ese perfil de personas desempleadas en situación o riesgo de exclusión social, las empresas de inserción surgen como un dispositivo a caballo entre las estrategias de formación y el acceso directo al empleo. Las entidades de iniciativa social encuentran en las empresas de inserción un dispositivo que considera - desde un acompañamiento personalizado- la formación y la adquisición de habilidades y capacidades laborales y sociales, fundamentalmente en el puesto de trabajo (además de otras posibles intervenciones añadidas no asociadas al perfil laboral), todo ello, en el marco de un entorno empresarial y laboral lo más normalizado posible. Por ello, optan por desarrollar iniciativas económicas que operen en el mercado como cualquier otro tipo de empresa, tanto en cuanto a su actividad competitiva como en cuanto a su funcionamiento interno y las relaciones laborales que se establecen. Eso sí, bajo el amparo de las propias entidades sociales y teniendo como objetivo principal la mejora de la empleabilidad y la inserción laboral en el mercado ordinario de estas personas.

Hay que señalar, además, que en Europa (especialmente en las áreas francófonas) ya se estaban poniendo en marcha iniciativas similares, con las que las entidades sociales del Estado español entraron en contacto. Asimismo, fueron este tipo de entidades vinculadas a la inserción sociolaboral las que, al adentrarse en el ámbito del emprendizaje económico, dieron origen a diversas redes y espacios de trabajo compartido, lo que contribuyó a la extensión y visibilidad de esta nueva modalidad empresarial y de esta estrategia denominada en el propio sector social de 'inserción por lo económico'.

Particularmente, cabe señalar en sus orígenes la diferenciación que se hacía entre las empresas de inserción de carácter 'finalista' o las de carácter 'transitorio' para las personas contratadas y en proceso de inserción. El debate radicaba en si estas empresas debían ser consideradas como un 'trampolín' al mercado laboral y empresarial ordinario o si, por el contrario, debían ser empresas donde las personas completan su inserción laboral definitiva. No sería hasta su regulación, ya en la década de 2000, que se reconocería el modelo transitorio para 
las personas en proceso de inserción sociolaboral. En el caso del Estado español, actualmente el contrato de inserción puede celebrarse por un periodo máximo de tres años².

Hay que reconocer asimismo que, desde su nacimiento y prácticamente hasta la actualidad, las empresas de inserción han desarrollado un proceso de progresivo reconocimiento e institucionalización, aspectos que han derivado tanto en su regulación como en el impulso de diferentes medidas de fomento. Este proceso ha dado también carta de legitimidad a este sector en el ámbito de la economía social, y ha permitido también su reconocimiento en el catálogo de instrumentos al servicio de las políticas activas de empleo.

Resumimos a continuación las principales leyes y regulaciones sobre las empresas de inserción de carácter estatal. La Ley 44/2007 de 13 de diciembre, para la regulación del régimen de las empresas de inserción, las define en su artículo 4 de la siguiente manera:

Tendrá la consideración de empresa de inserción aquella sociedad mercantil o sociedad legalmente constituida que, debidamente calificada por los organismos autonómicos competentes en la materia, realice cualquier actividad económica de producción de bienes y servicios, cuyo objeto social tenga como fin la integración y formación sociolaboral de personas en situación de exclusión social como tránsito al empleo ordinario.

La Ley 5/2011, de 29 de marzo, de Economía Social, reconoce y facilita la actividad de un sector de empresas cuyo denominador común es la primacía de las personas que componen las estructuras productivas, de las personas consumidoras y del fin social, el compromiso con el desarrollo social, la cohesión social y la sostenibilidad. Esta ley reconoce a las empresas de inserción como un subsector específico dentro de la economía social.

La Ley 31/2015, de 9 de septiembre, por la que se modifica y actualiza la normativa en materia de autoempleo y se adoptan medidas de fomento y promoción del trabajo autónomo y de la economía social, supone un hito relevante en el desarrollo del sector de las empresas de inserción en el Estado español, ya que, entre otras cuestiones, introduce tres importantes medidas para el fomento de las empresas de inserción, que a continuación enumeramos y que desarrollaremos más ampliamente a lo largo del artículo:

- Las empresas de inserción son declaradas entidades prestadoras de servicios de interés económico general. De esta forma, se las reconoce como una fuente de creación de empleo

${ }^{2}$ Tal y como señala el artículo 15.4 de la Ley 44/2007, de 13 de diciembre, para la regulación del régimen de las empresas de inserción. para aquellas personas con mayores dificultades para acceder al mercado laboral. Esta declaración supone un nuevo espacio para el crecimiento del sector, ya que posibilita el desarrollo de una nueva hoja de ruta en materia de economía y fiscalidad para las empresas de inserción.

- Se incluye a las empresas de inserción como posibles beneficiarias de los contratos reservados de las administraciones públicas, modificando la disposición adicional quinta del texto refundido de la Ley de Contratos del Sector Público33.

- Con el objetivo de facilitar el tránsito de las personas trabajadoras de las empresas de inserción a las empresas ordinarias, se amplían las bonificaciones existentes en las cuotas empresariales por la contratación de dichas personas. Para las empresas que contratan a personas que han finalizado sus itinerarios en las empresas de inserción, esto supone unas bonificaciones en las cuotas de la Seguridad Social de 1.650 euros durante el primer año de contrato.

Estas tres importantes medidas facilitan, como decíamos, el desarrollo de una nueva hoja de ruta para el sector de las empresas de inserción, que en los próximos años se enfrentará a dos importantes retos: el desarrollo de la declaración de las empresas de inserción como entidades prestadoras de servicios de interés económico general y la aplicación de los contratos reservados. Estos dos retos son, a la vez, grandes oportunidades para ayudar a las empresas de inserción a consolidarse como herramientas de las políticas activas de empleo en el Estado español en su conjunto y, específicamente, en la Comunidad Autónoma Vasca (CAV).

En el caso de la CAV, la regulación de las empresas de inserción se remonta al año 2000, en el que se aprueba el Decreto 305/2000, de 26 de diciembre, por el que se regula la calificación de las empresas de inserción, se establece el procedimiento de acceso y se crea el registro de empresas de inserción. Este decreto fue actualizado en 2008 , tras la aprobación de la ley estatal y para adecuarse a ella (Decreto 182/2008).

\section{Las empresas de inserción como instrumento eficiente de lucha contra la exclusión social y la pobreza.}

Según la European Network of Social Integration Enterprises, en Europa existen en la actualidad más de 2.500 empresas de inserción, con alrededor de 400.000 personas asalariadas. Empresas asociadas en 28 redes estatales y regionales en 21 países europeos, y si bien hay diferencias notables en

${ }^{3}$ La Ley 9/2017, de 8 de noviembre, de Contratos del Sector Público, aprobada el 19 de octubre de 2017 por el Congreso de los Diputados, recoge esta posibilidad en la disposición adicional cuarta. 
cuanto a regulación, comparten el objeto social de la inserción sociolaboral a través de la actividad económica. En el caso del Estado español, en 2015 las empresas de inserción estaban agrupadas en 12 redes empresariales de carácter autonómico, que constituían la Federación de Asociaciones Empresariales de Empresas de Inserción y representaban a alrededor de 200 empresas, que generan 5.061 empleos directos (Faedei, 2016).

Tal y como ya hemos señalado, las empresas de inserción nacen como un instrumento innovador y eficaz para luchar contra la pobreza y la exclusión social a través de la inserción por lo económico, es decir, la inclusión social a través de la integración sociolaboral en el mercado de trabajo. En este sentido, las empresas de inserción tienen algunos rasgos singulares:

- Son estructuras productivas, promovidas por entidades sin ánimo de lucro, que trabajan en el mercado produciendo bienes y servicios.

- Son instrumentales, es decir, no son un fin en sí mismas, sino que se crean como un instrumento de intervención sociolaboral para preparar a personas que se encuentran en situación de vulnerabilidad o exclusión social de cara a incorporarse al mercado laboral ordinario, aumentando su empleabilidad.

- Son transitorias, ya que tienen la voluntad de preparar a las personas para el tránsito hacia el mercado ordinario.

- El acompañamiento es el modelo de intervención en las empresas de inserción: las medidas de intervención y acompañamiento consisten en un conjunto de actuaciones encaminadas a satisfacer o resolver problemas específicos derivados de la situación de exclusión. Como modelo, se basa en la centralidad de las personas y el respeto hacia ellas, lo que implica tomar como punto de partida las necesidades e intereses de la persona contratada. El acompañamiento se realiza en torno a dos ejes interconectados que caracterizan a las empresas de inserción: el desempeño laboral y la mejora de la empleabilidad. El acompañamiento 4 cuenta con unas fases comunes - selección, acogida, actualización del proyecto profesional, desempeño laboral, mejora de la empleabilidad y transición-y se realiza en función de un esquema de competencias que se estructura en tres áreas: personales, sociolaborales y técnico-profesionales.

Queremos resaltar, sin embargo, que el elemento diferencial de las empresas de inserción respecto a otros instrumentos de las políticas activas de empleo y otros mecanismos de lucha contra la pobreza radica en que no consume recursos económicos a fondo perdido, sino que la inversión pública produce un retorno a la sociedad tanto fiscal (vía impuesto de actividad económica, IRPF) y económico (reduciendo el número de personas en desempleo que reciben prestaciones y dinamizando la economía) como en términos de cohesión y justicia social.

\subsection{Retorno económico}

En Euskadi, Gizatea, la asociación representativa del sector de las empresas de inserción (en 2016 agrupaba a 44 de las 45 empresas registradas) viene realizando, desde 2009 , el ejercicio de calcular el retorno económico de estas empresas a las administraciones públicas vascas. Al intervenir en sectores muy diversos (Figura 1), desde la construcción, hasta la limpieza o el reciclaje, con niveles salariales diferentes, se ha fijado una media

4 Para profundizar en el modelo de acompañamiento, puede consultarse Fernández, Galarreta y Martínez (2007). 
Tabla 1. Contribución de las empresas de inserción por las personas en inserción que tienen contratadas (2016)*

\begin{tabular}{|l|c|c|c|}
\cline { 2 - 2 } \multicolumn{1}{c|}{} & \multicolumn{1}{c|}{$\begin{array}{c}\text { Importe por puestos } \\
\text { de inserción/año ( } \boldsymbol{\ell})\end{array}$} & \multirow{2}{*}{$\begin{array}{c}\text { No de puestos } \\
\text { de inserción }\end{array}$} & $\begin{array}{c}\text { Total de ingresos } \\
\text { a las administraciones } \\
\text { públicas (€) }\end{array}$ \\
\hline Seguridad Social empresarial & $4.689,10$ & \multirow{4}{*}{} & $1.985 .458,72$ \\
\hline Seguridad Social trabajador/a & $1.171,74$ & \multirow{2}{*}{423} & $496.136,74$ \\
\hline IRPF & 773,34 & & $327.446,21$ \\
\hline IVA & 841,50 & & $356.307,55$ \\
\hline Impuesto sobre Sociedades & 147,85 & & $62.601,63$ \\
\hline Otros tributos & 148,35 & & $62.815,83$ \\
\hline Total & $7.771,87$ & & $2.926 .079,30$ \\
\hline
\end{tabular}

Retorno por puesto de inserción

$3.290 .766,67$

* Se ha tomado como base un salario bruto anual de $15 \cdot 529,88$ euros. Fuente: Gizatea (en prensa).

que permita hacer las comparaciones pertinentes. En este caso, se ha tomado como base un salario bruto anual de una persona trabajadora de inserción de 15.529,88 euros (Gizatea, 2016). Sobre este importe, se han aplicado los conceptos de Seguridad Social empresarial, Seguridad Social de la persona trabajadora, IRPF, IVA, impuesto de sociedades y otros tributos (Tabla 1).

Así, el retorno por puesto de inserción en 2016 fue de $7.771,87$ euros. Si hablamos en términos globales, el retorno por los 423 puestos de inserción en las empresas de inserción vascas asociadas a Gizatea durante 2016 fue de $3.287 .501,01$ euros.

\subsection{Comparación entre ayudas y retornos: coste total de la plaza de inserción}

Para comparar las ayudas públicas que perciben las empresas de inserción y el retorno que éstas hacen a las administraciones públicas, se ha hecho el siguiente cálculo:

$$
\frac{\text { total ayudas públicas - total retorno social }}{\text { total de puestos de inserción }}
$$

Así, con las estimaciones realizadas, el coste real de una plaza de inserción en 2015 fue de 7.547,32 euros.

Tabla 2. Ayudas, retornos y coste real de una plaza en una empresa de inserción. Euskadi, 2016 (en euros)

\begin{tabular}{|l|c|}
\hline $\begin{array}{l}\text { Subvención a empresas de inserción por puesto } \\
\text { de inserción }\end{array}$ & $13.261,22$ \\
\hline Retorno por puesto de inserción & $7.771,87$ \\
\hline Coste real & $5.489,34$ \\
\hline
\end{tabular}

Fuente: adaptado de Gizatea (en prensa).

\subsection{Comparación del coste de una persona en el sistema de garantía de ingresos y en una empresa de inserción}

Para comparar el coste de una persona en el sistema de garantía de ingresos y en una empresa de inserción, se han considerado dos cuestiones: la media de lo que una persona recibe anualmente de renta de garantía de ingresos y el importe recibido anualmente por otros apoyos sociales, a partir de datos extraídos de diferentes estudios 5 . Según este cálculo, el coste anual de una persona que está percibiendo la renta mínima o similar sería de 12.091,16 euros.

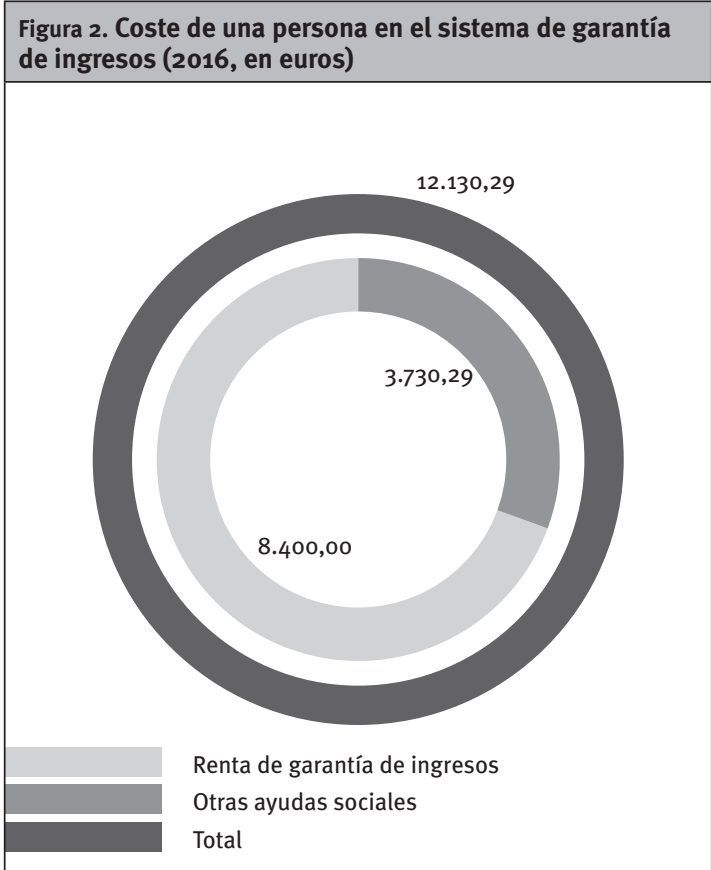

Fuente: adaptado de Gizatea (en prensa).

Con estos datos, se puede comparar lo que le cuesta a la Administración una persona en una empresa de inserción y lo que le cuesta en caso de que esa persona esté cobrando la renta de garantía de ingresos. Estimamos así que existe un ahorro de 4.543,84 euros por plaza de inserción (Figura 3).

5 Uno de los estudios en los que nos hemos basado para estimar este coste es Sarasa y Sales (2009). Esta aproximación a los costes unitarios fue un primer paso para avanzar en el camino de una valoración adecuada de los costes de los servicios, y dado que se trata de una aproximación exploratoria, dichos datos deben tomarse con la debida precaución. 


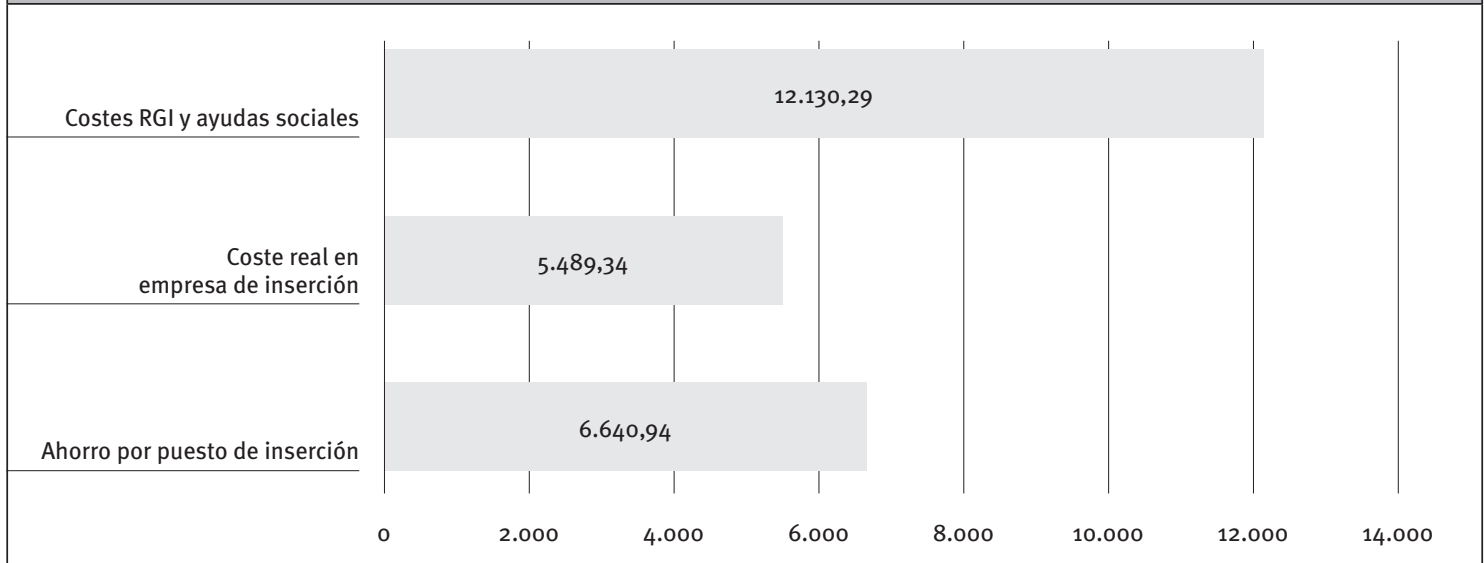

RGI: renta de garantía de ingresos. Fuente: Gizatea (en prensa).

Si a esta justificación puramente económica, le añadimos la contribución de las empresas de inserción a generar empleo y riqueza a corto y medio plazo, y a lograr una sociedad más equitativa y cohesionada a largo plazo, nos encontramos con que las empresas de inserción son una de las herramientas más eficaces y eficientes en la lucha contra la exclusión social.

\section{Panorámica del sector en Euskadi: principales indicadores económicos y de empleo}

Si bien empieza a configurarse de algún modo en la década de los ochenta, el sector de las empresas de inserción no se articula hasta principio de la década de 2000, por lo que podemos decir que es de reciente creación. La ley que regula el sector cumple justo este año una década, y lo mismo puede decirse de las asociaciones territoriales que las representan, siendo éste el caso de Gizatea, que en 2017 celebra su décimo aniversario. Hasta 2009, no existe, por tanto, información sistemática de su comportamiento específico, comenzándose a recoger en ese año datos sobre las empresas de inserción a través del balance social, una herramienta que permite establecer procedimientos para la recogida sistemática de información y que se centra en los siguientes indicadores: datos generales, información social, inserción laboral, información económica, retorno social, información sobre la clientela y sobre la gestión de las empresas. Esta recogida de información se realiza a escala estatal, liderada por Faedei. Si bien anualmente se publica una memoria social con los datos consolidados de las empresas de inserción de todo el Estado, en el caso de Euskadi Gizatea publica además su propia memoria social desde $2009^{6}$.

6 Véase 〈http://www.gizatea.net/publicaciones/?_sft_cat_ publicacion=memoria-social .
A continuación, presentamos algunas de las principales conclusiones obtenidas del análisis de la información sistematizada de carácter evolutivo de las empresas de inserción que aparece en la revisión de los balances sociales de Gizatea de los años 2009 a 2016:

- Crecimiento limitado de los puestos de inserción, que se ve frenado durante la crisis, la cual afecta principalmente a los puestos de no inserción: si bien los efectos de la crisis se notaron en la CAV más tarde que en el resto del Estado español, se observa un claro descenso de los puestos de inserción7, que alcanza su momento más bajo en 2014, con 351 puestos frente a los 474 de 2011, y 224 puestos de no inserción, frente a los 319 de 2010. En 2015, se vislumbra ya una cierta recuperación, que se afianza en 2016, donde los datos muestran un incremento de un $8,5 \%$ en los puestos de inserción respecto a 2015.

- El empleo generado por el sector, si bien se ve frenado en 2014, vuelve a incrementarse en 2015 y 2016, especialmente el empleo para personas en proceso de inserción: con dos empresas menos que en 2015 (44 frente a 46), las empresas de inserción vascas asociadas a Gizatea emplean en 2016 a 1.123 personas, 665 de las cuales en proceso de inserción. Se vuelve así casi a niveles previos a la crisis, concretamente a 2011, año en el que más empleos se generaron y el número de personas en procesos de inserción alcanzó las 671.

- Las empresas de inserción se muestran como una herramienta eficaz para la activación laboral de las personas perceptoras de rentas de garantía de ingresos: desde 2009, las empresas de inserción vascas han visto cómo el número de personas en proceso de inserción que anteriormente percibían

7 Diferenciamos entre puesto y persona: un puesto o plaza sig. nifica una jornada completa de trabajo, mientras que una persona puede ocupar un puesto a jornada completa o tener una dedicación parcial y que dicho puesto sea ocupado por varias personas. 
la renta de garantía de ingresos sufría un incremento constante y significativo, pasando de las 226 en 2009 a las 490 que arrojan los datos de 2016. Este último año, el $74 \%$ de las personas trabajadoras en proceso de inserción recibían con anterioridad la renta de garantía de ingresos.

- La incorporación al mercado ordinario de las personas que finalizan su proceso en las empresas de inserción vascas, estable durante 2014 y 2015, vuelve a aumentar en 2016: de acuerdo con los datos del balance social de 2016, el 61,48\% de las personas en proceso de inserción que finalizaron su proceso en estas empresas se ha incorporado al mercado laboral ordinario, lo que supone un incremento del $6 \%$ respecto a 2015 y de casi un $20 \%$ respecto a 2012, año en el que se obtuvieron los peores resultados en inserción laboral.

- Se reduce el presupuesto destinado a ayudas públicas específicas para las empresas de inserción vascas: la convocatoria de ayudas en la CAV es plurianual, es decir, que el monto total asignado a cada convocatoria no se imputa sólo a ese ejercicio, ya que se compromete gasto para, como mínimo, otros tres años más, por lo que resulta complejo determinar el gasto concreto para cada año analizado. No obstante, si atendemos al monto total de las convocatorias, observamos que en 2012 se reduce en más de un millón de euros el presupuesto asignado y comprometido para los próximos años, si bien se mantienen todas las líneas de ayudas sin variaciones en sus máximos establecidos. En 2013, vuelve a haber una reducción considerable de 800.000 euros, retirándose además algunas líneas subvencionables, como la correspondiente a inversiones en activos fijos. En total, en el periodo 2010-2016 el presupuesto asignado se ha reducido en un $19 \%$ (pasando de 10.281 .280 a 8.200.000 euros).

- Las ventas son la principal fuente de ingresos de las empresas de inserción vascas, manteniéndose estables en los últimos años en relación con el total de ingresos: los datos de 2016 apuntan unos ingresos totales de 29.743.173,08 euros, de los cuales un $75 \%$ procede de la facturación por venta de productos y servicios. Queremos resaltar aquí que, del total de las ventas, un $78 \%$ procede de clientela privada, y un $22 \%$, del sector público. Por lo tanto, estas empresas operan en el mercado de carácter privado, y su contratación por parte de las administraciones públicas sigue siendo muy limitada y mayoritariamente sin cláusulas sociales. En cuanto a las ayudas, que suponen un $25 \%$ de los ingresos totales, un $80 \%$ son específicas a empresas de inserción, y destaca en 2016 un incremento del $7 \%$ en ayudas privadas.

\section{Medidas de fomento de las empresas de inserción}

Las empresas de inserción, por la función social que desempeñan, por el sobrecoste que conlleva la contratación de personas poco cualificadas en situación de exclusión social, así como por el desarrollo del trabajo de acompañamiento, formación y apoyo en los itinerarios personalizados de inserción, pueden ser beneficiarias de determinadas medidas y ayudas para su fomento. Éstas pueden ser clasificadas en los epígrafes que se señalan a continuación:

- Ayudas públicas para su creación (estudios de viabilidad previos y gastos de constitución), para la contratación (de personas en proceso de inserción, así como de personal técnico de acompañamiento a la inserción y de acompañamiento a la producción), para inversiones, para la realización de estudios cuyo objeto sea la ampliación de líneas de actividad, para el desarrollo de actividades formativas con las personas en proceso de inserción, o para el sostenimiento de las estructuras asociativas de las empresas, entre otras. Estas ayudas se dan en el marco de las comunidades autónomas, siendo variables en tipo y desiguales en cuantía, en función del territorio. En el caso de la CAV, existe una orden de ayudas ${ }^{8}$, que en la convocatoria de 2017 contempla ayudas para la creación y el mantenimiento de puestos de trabajo destinados a personas en proceso de inserción, a técnicos de acompañamiento a la producción y a técnicos especializados en acciones de acompañamiento a la inserción; así como para la asistencia técnica y la formación.

- Bonificaciones a las cuotas a la Seguridad Social en los contratos de trabajo para las personas en situación de exclusión social'9.

- Bonificaciones a la contratación de personas que hayan finalizado su itinerario en una empresa de inserción ${ }^{10}$.

- La obligación de las instituciones públicas de fijar porcentajes mínimos de reserva del derecho a participar en los procedimientos de adjudicación de determinados contratos o de determinados lotes de éstos a empresas de inserción o centros especiales de empleo de iniciativa social ${ }^{11}$.

\footnotetext{
${ }^{8}$ Orden de 4 de mayo de 2009, del Consejero de Justicia, Empleo y Seguridad Social, por la que se regulan las ayudas para la creación y el sostenimiento de las empresas de inserción.

9 Previstas en el artículo 16.3 a de la Ley 44/2007, de 13 de diciembre, para la regulación del régimen de las empresas de inserción; en el artículo 14.1b del Real Decreto-ley 4/2013, de 22 de febrero, de medidas de apoyo al emprendedor y de estímulo del crecimiento y de la creación de empleo; y en el artículo 3.2, de la Ley 31/2015, de 9 de septiembre, por la que se modifica y actualiza la normativa en materia de autoempleo y se adoptan medidas de fomento y promoción del trabajo autónomo y de la Economía Social.

${ }_{10}$ Prevista en el artículo sexto de la Ley $31 / 2015$, de 9 de septiembre, por la que se modifica y actualiza la normativa en materia de autoempleo y se adoptan medidas de fomento y promoción del trabajo autónomo y de la Economía Social.

${ }^{11}$ Establecida en el artículo cuarto de la Ley 31/2015, de 9 de septiembre, por la que se modifica y actualiza la normativa en materia de autoempleo y se adoptan medidas de fomento y promoción del
} 


\section{Medidas de fomento de las empresas de inserción en el ámbito de la contratación pública}

\subsection{Contratos reservados para empresas de inserción}

Como hemos repetido a lo largo del artículo, y a pesar de los cambios que se están produciendo en este ámbito en los últimos años, el empleo constituye todavía hoy un factor determinante a favor de la inclusión social. Sin embargo, y aunque existe una legislación cada vez más favorable a la incorporación de cláusulas sociales en los contratos públicos, las oportunidades de empleo generadas por el sector público para las personas en situación o riesgo de exclusión social son claramente insuficientes. Por otro lado, la contratación pública desempeña un papel de suma importancia en la economía, hasta el punto de suponer en torno al $15 \%$ del PIB, por lo que cada vez que un ente público adjudica un contrato está produciendo un considerable efecto en el mercado y en el entorno.

La actual legislación de contratos ha reconocido de manera expresa e inequívoca la posibilidad de utilizar la contratación pública para la consecución de objetivos sociales, desde la Directiva 2014/24/UE del Parlamento Europeo y del Consejo, al Real Decreto $3 / 2011$, de 14 de noviembre por el que se aprueba el texto refundido de la Ley de Contratos del Sector Público; o la reciente Ley 31/2015, de 9 de septiembre, por la que se modifica y actualiza la normativa en materia de autoempleo y se adoptan medidas de fomento y promoción del trabajo autónomo y de la economía social. Además, la Ley 9/2017, de 8 de noviembre, de Contratos del Sector Público supone otro paso firme en materia de cláusulas sociales.

Una de las medidas para el fomento de las empresas de inserción introducidas por la Ley 31/2015 ha sido la modificación de la disposición adicional quinta del texto refundido de la Ley de Contratos del Sector Público que trata sobre los contratos reservados, recogida en la nueva Ley $9 / 2017$, de Contratos del Sector Público, en su disposición adicional cuarta, y que permite a cualquier administración pública "reservar la participación" en la licitación exclusivamente a centros especiales de empleo de iniciativa social y empresas de inserción ${ }^{12}$. Es decir, que solamente pueden presentarse y ser admitidas dichas tipologías de empresas, reconociéndose así sus especiales características, su carácter reglado y su beneficio social demostrado e incontestable. La disposición adicional cuarta obliga a las administraciones públicas a fijar porcentajes mínimos de reserva y a establecer las condiciones mínimas para garantizar el cumplimiento de dicha reserva.

trabajo autónomo y de la economía social; y en la disposición adicional cuarta de la Ley 9/2017, de 8 de noviembre, de Contratos del Sector Público.

${ }_{12}$ Para profundizar en este asunto, puede consultarse Lesmes y Álvarez de Eulate (2015).
El contrato reservado puede aplicarse a cualquier objeto contractual y sector de actividad, en cualquier tipo de contrato (de obra, de concesión de obra pública, de servicios, de gestión de servicios públicos, de suministro), cualquier procedimiento de adjudicación (abierto, restringido o negociado, menor, acuerdo marco) y cualquier importe; pueden reservarse lotes y, en la práctica, un contrato reservado se articula en un pliego de cláusulas como cualquier otra licitación. Su única particularidad es la limitación del derecho de participación, pues solamente podrán presentarse los centros especiales de empleo de iniciativa social y las empresas de inserción.

Esta medida de fomento tan importante para las empresas de inserción augura al sector un potencial de crecimiento importante en el Estado español, pero al ser muy reciente, de finales de $\mathbf{2 0 1 5}$, su cumplimiento es aún muy limitado. Algunas comunidades autónomas y entidades locales han fijado ya dichos porcentajes mínimos de reserva y han comenzado a reservar contratos a empresas de inserción, pero faltan todavía muchas más y, sobre todo, es importante que las administraciones públicas utilicen el contrato reservado de forma estratégica, cuantificada, planificada y coordinada con el sector, de forma que se genere para las empresas de inserción un mercado protegido que facilite su sostenimiento y su crecimiento.

Algunas claves para abordar la reserva de mercado tienen que ver con:

- La sensibilización tanto a representantes políticos como a personal técnico de las administraciones públicas. La normativa existe, pero hay que realizar una labor de concienciación en esta materia, facilitando experiencias y buenas prácticas y trabajando estratégicamente con agentes clave, como Eudel en el caso de la CAV.

- La vigilancia y seguimiento del cumplimiento de la Ley: la Administración es responsable de que la normativa se cumpla, y puede garantizar el cumplimiento de la reserva de diversas formas, por ejemplo, asignando unas cuantías o porcentajes a cada órgano de contratación, estableciendo verificadores, computando de forma pública y transparente las cuantías adjudicadas mediante contratos reservados, o incluso conformando mesas de seguimiento en las que participen representantes del sector de las empresas de inserción. Sin embargo, es importante que el propio sector realice también esta tarea, por ejemplo, seleccionando administraciones concretas e impulsando la puesta en marcha de estas comisiones de seguimiento en las que esté representado el sector o reconociendo públicamente a las administraciones que cumplen la ley, entre otras.

- El estudio de los mercados afines a la actividad de las empresas de inserción, analizando los contratos actuales de la Administración (Gobierno 
Vasco, diputaciones y ayuntamientos), tarea que podrían abordar las propias empresas a escala local, puesto que tienen un conocimiento más cercano del tipo de obras y servicios que contratan las administraciones de su ámbito territorial de actuación.

\subsection{Otras medidas de fomento en el ámbito de la contratación pública}

Además de los contratos reservados, hay otras medidas que pueden y deben impulsarse en el ámbito de la contratación pública, ya que, tal y como se señala en el artículo primero de la Ley 9/2017, de 8 de noviembre, de Contratos del Sector Público:

En toda contratación pública se incorporarán de manera transversal y preceptiva criterios sociales y medioambientales siempre que guarden relación con el objeto del contrato, en la convicción de que su inclusión proporciona una mejor relación calidad-precio en la prestación contractual, así como una mayor y mejor eficiencia en la utilización de los fondos públicos. Igualmente se facilitará el acceso a la contratación pública de las pequeñas y medianas empresas, así como de las empresas de economía social.

Así, otras medidas de fomento de las empresas de inserción que las administraciones públicas pueden y deben explorar e impulsar en el ámbito de la contratación son:

- El uso de cláusulas sociales en los contratos públicos como elemento integrador, introduciendo, por ejemplo, condiciones especiales de ejecución que favorezcan la contratación de personas provenientes de las empresas de inserción tras finalizar con éxito su itinerario; o condiciones especiales de ejecución que obliguen a subcontratar un porcentaje de la obra o servicio con empresas de inserción.

- División de los grandes concursos en lotes y limitación, cuando sea pertinente, del número de lotes al que pueden presentarse las empresas licitadoras, de forma que se generen oportunidades para las pymes $y$, consecuentemente, también para las empresas de inserción.

- Favorecer alianzas entre empresas de inserción y empresas ordinarias, impulsando la responsabilidad social del tejido empresarial en la inserción laboral de personas con mayores dificultades de empleabilidad. Esto contribuiría al conocimiento de las empresas de inserción por parte del sector empresarial, lo que podría abrir nuevas oportunidades de colaboración en el ámbito privado, así como posibilidades de tránsito al mercado ordinario para las personas en proceso de inserción.

- Impulso de convenios específicos con la Administración en determinados sectores.

\section{Las empresas de inserción como entidades prestadoras de servicios de interés económico general}

La calificación de las empresas de inserción como entidades prestadoras de servicios de interés económico general (SIEG) se recoge en la Ley $31 / 2015$, de 9 de septiembre, por la que se modifica y actualiza la normativa en materia de autoempleo y se adoptan medidas de fomento y promoción del trabajo autónomo y de la economía social. En su artículo tercero, que modifica la Ley 5/2011, de 29 de marzo, de Economía Social, se añade un apartado 4 al artículo 5 de dicha regulación, que dice así:

\section{Se declaran entidades prestadoras de Servicios de Interés Económico General los Centros Especiales de Empleo y las Empresas de Inserción constituidas y calificadas como tales según su normativa reguladora. Asimismo, podrá extenderse esta declaración a cualesquiera otras entidades de la economía social que tengan por objeto igualmente la inserción laboral de colectivos en riesgo de exclusión, conforme a lo que se establezca reglamentariamente.}

Se trata de una modalidad que permite a los Estados miembros de la Unión Europea determinar qué tipo de servicios pueden ser considerados de interés general, aunque tengan un contenido económico y sean prestados por agentes que participan en el mercado, como es el caso de las empresas de inserción. Esta declaración es muy importante para el sector y su desarrollo es una gran oportunidad para ayudar a las empresas de inserción a consolidarse como herramientas de las políticas activas de empleo.

La declaración permite, en primer lugar, a la administración pública exigir el cumplimiento, por parte de las entidades, de los fines y misión por los que se les reconoce dicha calificación. En segundo lugar, justifica determinadas ayudas y medidas de fomento para el impulso de estas entidades, en la medida que se les reconoce un sobrecoste en el desarrollo de su misión considerada como SIEG. Estas ayudas pueden consistir en subvenciones, posibilidad de acceso a créditos en condiciones favorables, beneficios fiscales o prestación de garantías por parte de la Administración a las entidades, entre otras medidas (Paricio, 2013).

La declaración de las empresas de inserción como entidades prestadoras de SIEG dota de seguridad jurídica a las ayudas públicas que éstas reciben desde hace años por parte de algunas comunidades autónomas, que, en algunos casos, pueden superar los umbrales de los minimis ${ }^{13}$ establecidos por la

13 Las ayudas de minimis son las que pueden conceder los Es tados miembros de la UE a sus empresas, que tienen consecuencias limitadas sobre la competencia y que no son de comunicación previa a la Comisión Europea antes de su concesión. La Comisión establece unos umbrales máximos para estas ayudas sujetas a minimis, permitiendo determinadas cantidades en un espacio temporal concreto. 
Unión Europea. Asimismo, justifica otras medidas de fomento de las empresas de inserción reconocidas en la Ley 31/2015, así como las que se puedan impulsar en el futuro, como un tratamiento fiscal especial, entre otras, lo que encierra un notable potencial para el desarrollo y crecimiento del sector.

\section{Retos presentes y futuros de las empresas de inserción vascas}

Desde que se aprobó en el País Vasco el primer decreto de regulación de las empresas de inserción (diciembre de 2000) y la primera orden de ayudas (diciembre de 2002), han sido muchos los cambios sociales, culturales y económicos que han acontecido, tanto en nuestra sociedad como en el ámbito de la exclusión e inclusión social, y en el del empleo. También son muchos los cambios que se han producido en el modo de hacer de las empresas de inserción vascas, en su profesionalidad, en su reconocimiento o en sus relaciones con las instituciones públicas. Ciertamente las empresas de hoy no son iguales que las que nacieron en los noventa sin apoyo público inicial, y el sector ha crecido tanto cualitativa como cuantitativamente.

A pesar de ello, se mantienen las intuiciones iniciales que dieron lugar a esta modalidad original de impulsar el empleo inclusivo a través de una actividad económica y empresarial. Y, en ese sentido, es oportuno seguir reivindicando la función social que tienen estas empresas y sus características básicas: (1) iniciativas económicas de carácter no lucrativo; (2) impulsadas, a su vez, por entidades no lucrativas especializadas en el ámbito del empleo y la inclusión social; (3) que operan en el mercado como cualquier otra empresa; (4) cuyo objetivo primordial es mejorar la empleabilidad y conseguir la inserción sociolaboral de personas desempleadas en situación o riesgo de exclusión social; (5) a través de un itinerario personalizado, de no más de tres años de duración, en el que se realiza un acompañamiento social y técnico profesional en el propio desempeño laboral, y a través de otros apoyos formativos y sociales. Son iniciativas, por tanto, encuadradas en las denominadas políticas activas de empleo, que además contribuyen al fortalecimiento de una economía social y solidaria, a la construcción de un modelo de desarrollo local inclusivo y al impulso de la cohesión social en la comunidad más cercana.

Si bien mantiene dichos principios fundamentales, en determinadas coyunturas -como la crisis económica, el aumento del desempleo, los cambios institucionales en las políticas de empleo e inclusión social- el modelo se resiente, tiene dificultades para adaptarse a nuevos contextos y puede correr el riesgo de estancarse. Conscientes de esta situación, desde Gizatea hemos llevado a cabo en 2016 y 2017 un proceso reflexivo profundo, en el que hemos identificado varios retos y líneas estratégicas para el avance tanto de las empresas de inserción vascas, como de Gizatea como su agrupación empresarial, cuyo objeto es precisamente promover la mejora de sus empresas y alcanzar mayores y mejores cuotas de interlocución institucional y social.

Así, las empresas de inserción vascas agrupadas en Gizatea, tenemos el convencimiento de que es posible:

- Triplicar en tres años (2020) el número de personas en proceso de inserción en nuestras empresas.

- Que el $80 \%$ de estas personas obtengan resultados satisfactorios para ellas que sean evaluados en el marco de las políticas públicas de empleo.

- Que las empresas de inserción estén presentes en todas las comarcas de Euskadi.

- Que cuenten con un diseño y encaje adecuado $y$ reconocido entre los diversos instrumentos y agentes relevantes para los procesos de inclusión sociolaboral, a la altura de la envergadura y complejidad de los retos del empleo y la inclusión en nuestra sociedad.

Para ello, nos proponemos:

a. Impulsar el crecimiento del sector:

- Fomentando desarrollos normativos favorables para las empresas de inserción a escala estatal, a través de Faedei y participando activamente en la redacción de nuevas normativas para las empresas de inserción en Euskadi.

- Trasladando propuestas de interés para las empresas de inserción en otro tipo de desarrollos normativos relacionados con el empleo, la economía social o la inclusión.

- Incorporando las empresas de inserción a las estrategias y políticas activas de empleo, sociales y de inclusión en los diferentes niveles institucionales y competenciales.

- Impulsando las cláusulas sociales y los contratos reservados, favoreciendo así el acceso de las empresas de inserción a la contratación pública.

- Valorando y aprovechando oportunidades existentes para el desarrollo de nuevos mercados en planes de desarrollo local u otro tipo de políticas de promoción económica, así como en las prácticas de responsabilidad social de las empresas ordinarias.

- Promoviendo espacios y actividades que faciliten el conocimiento mutuo y la relación entre las empresas de inserción socias, así como el consumo interno de bienes y servicios.

- Impulsando dinámicas que promuevan la innovación o la identificación de nuevos sectores de actividad.

b. Incidir en agentes clave:

- Manteniendo un alto grado de interlocución con las instituciones públicas (Departamento 
de Empleo y Políticas Sociales, Lanbide, administraciones forales y locales), para lograr el reconocimiento de la red y del sector de las empresas de inserción.

- Incrementando el grado de interlocución y relación de la red con los agentes políticos y sociales (organizaciones políticas, sindicales, empresariales).

- Promoviendo el desarrollo y participando activamente en espacios de colaboración con las redes de la economía social, a través de la participación en la Red Vasca de Economía Social-Euskal Gizarte Ekonomia Sarea (EGES).

- Participando activamente en Faedei, a través de ésta, en la European Network of Social Integration Enterprises (ENSIE), y manteniendo la relación de colaboración y apoyo mutuo con otras asociaciones territoriales de las empresas de inserción.

- Potenciando la colaboración estrecha con la Red de Economía Alternativa y SolidariaREAS Euskadi, así como con los agentes de la economía solidaria (Banca Ética Fiare, Mercado Social).

- Contribuyendo a la consolidación de ekalNRedes para la Inclusión Social en Euskadi, fomentando el desarrollo de espacios compartidos.

- Contribuyendo al proceso de estructuración y fortalecimiento del tercer sector social vasco, a través de la participación en Sareen Sarea.

c. Aumentar la visibilidad en la sociedad vasca del valor añadido, el carácter innovador y los retornos económicos y sociales de las empresas de inserción:

- Continuando con la difusión anual de los resultados del balance social y profundizando el análisis de los datos.
- Desarrollando actuaciones dirigidas a promover la extensión de la marca 'empresa de inserción'.

- Desarrollando y poniendo en marcha herramientas de comunicación para el impulso social de Gizatea y las empresas de inserción vascas.

d. Consolidar el modelo de acompañamiento a la inserción:

- Difundiendo y facilitando herramientas para el trabajo de acompañamiento a la inserción.

- Llevando a cabo procesos de evaluación y perfeccionamiento del modelo.

- Promoviendo acciones formativas en cuestiones relacionadas con el acompañamiento a la inserción.

- Avanzando en las labores de intermediación laboral en el tránsito al mercado laboral ordinario de las personas trabajadoras de inserción.

e. Fortalecer Gizatea como red de referencia en Euskadi de las empresas de inserción:

- Promoviendo su interlocución institucional y social, así como el incremento de su capacidad para ofrecer servicios a las empresas de inserción.

Las empresas de inserción vascas deberán afrontar estos retos con creatividad, innovación, ilusión y cooperación, tal y como lo hicieron en su surgimiento, así como con la persistencia que han demostrado a lo largo de su trayectoria a la hora de reivindicar y obtener el reconocimiento jurídico y político que merecen y que en la actualidad tienen. 
ASKUNZE, C. (2016): “Empresas de Inserción en la economía social. Herramientas para la inclusión sociolaboral", Revista Jurídica de Economía Social y Cooperativas, no 29.

ESPAÑA (2017): “Ley 9/2017, de 8 de noviembre, de Contratos del Sector Público por la que se transponen al ordenamiento jurídico español las Directivas del Parlamento Europeo y del Consejo 2014/23/UE y 2014/24/UE, de 26 de febrero de 2014", Boletín Oficial del Estado, no 272, 9-11-17, págs. 107.714108.007 [<https://www.boe.es/buscar/doc. php?id=BOE-A-2017-12902〉].

- (2015): "Ley 31/2015, de 9 de septiembre, por la que se modifica y actualiza la normativa en materia de autoempleo y se adoptan medidas de fomento y promoción del trabajo autónomo y de la Economía Social", Boletín Oficial del Estado, nํ 217, 10-9-15, págs. 79.82479.848 [shttps://www.boe.es/buscar/doc. php?id=BOE-A-2015-9735'].

- (2013): "Real Decreto-ley 4/2013, de 22 de febrero, de medidas de apoyo al emprendedor y de estímulo del crecimiento y de la creación de empleo", Boletín Oficial del Estado, no 47, 23-213, págs. 15.219-15.271 [<https://www.boe.es/ buscar/doc.php?id=BOE-A-2013-2030〉].

- (2011): “Ley 5/2011, de 29 de marzo, de Economía Social”, Boletín Oficial del Estado, no 76, 30-311, págs. 33.023-33.033 [<http://www.boe.es/ buscar/doc.php?id=BOE-A-2011-5708>].

- (2011): "Real Decreto 3/2011, de 14 de noviembre, por el que se aprueba el texto refundido de la Ley de Contratos del Sector Público", Boletín Oficial del Estado, no 276, 16-11-11, págs. 117.729117.914 [khttps://www.boe.es/buscar/doc. php?id=BOE-A-2011-17887)].
- (2007): “Ley 44/2007, de 13 de diciembre, para la Regulación del Régimen de las Empresas de Inserción”, Boletín Oficial del Estado, no 299, 14-12-07, págs. 51.331-51.339 [khttp://www.boe. es/buscar/doc.php?id=BOE-A-2007-21492〉].

EUROPEAN NETWORK OF SOCIAL INTEGRATION ENTERPRISES $(\mathrm{s} / \mathrm{f})$ : [〈http://www.ensie.org〉].

FAEDEl (2016): Memoria Social 2015, Madrid, Federación de Asociaciones Empresariales de Empresas de Inserción [khttp://www.faedei.org/images/ docs/documento64.pdfs].

FERNÁNDEZ, A.; GALARRETA, J.; y MARTÍNEZ, I. (2007): Manual de acompañamiento en las empresas de inserción: procesos y herramientas. Una propuesta desde la práctica, Bilbao, REAS Euskadi [rhttp://www.economiasolidaria.org/ files/manual_acompa\%C3\%B1amiento.pdf〉].

GIZATEA (en prensa): Memoria Social 2016. Las empresas de inserción en el País Vasco, Bilbao, Gizatea.

- (2016): Memoria Social 2015. Las empresas de inserción en el País Vasco, Bilbao, Gizatea [<http://www. gizatea.net/wp-content/uploads/2015-GizateaMemoria-cast.pdf〉].

LESMES, S.; y ÁLVAREZ DE EULATE, L. (2015) : Guía para la aplicación de contratos reservados para empresas de inserción, Bilbao, REAS Euskadi [<http://www.gizatea.net/uploads/migration files/Guia\%2ocontratos\%2oreservados $\% 20$ El_cas.pdf〉].

PAÍS VASCO (2009): “Orden de 4 de mayo de 2009, del Consejero de Justicia, Empleo y Seguridad Social, por la que se regulan las ayudas para la creación y el sostenimiento de las empresas de inserción", Boletín Oficial del País Vasco, no 98, 26-5-09, págs. [khttps://www.euskadi.eus/yz2-bopv/es/ bopv2/datos/2009/05/0903002a.shtmls]. 
- (2008) “Decreto 182/2008, de 11 de noviembre, por el que se regula la calificación de empresas de inserción, se establece el procedimiento de acceso a las mismas y su registro", Boletín Oficial del País Vasco, no 225, 24-11-08 [rhttps://www.euskadi.eus/y22-bopv/es/ bopv2/datos/2008/11/0806515a.shtml>].

- (2002): “Orden de 11 de diciembre de 2002, del Consejero de Justicia, Empleo y Seguridad Social, por la que se regulan las ayudas para la creación y el sostenimiento de las empresas de inserción", Boletín Oficial del País Vasco, no 247, 27-1202 ['https://www.euskadi.eus/y22-bopv/es/ bopv2/datos/2002/12/0207386a.shtml>].

- (2000) "Decreto 305/2000, de 26 de diciembre, por el que se regula la calificación de las empresas de inserción, se establece el procedimiento de acceso y se crea el registro de empresas de inserción”, Boletín Oficial del País Vasco, n-0 24, 2-2-01, págs. 1.900-1.913 [<https:// www.euskadi.eus/y22-bopv/es/bopv2/ datos/2001/02/0100592a.shtml>].

PARICIO, E. (2013): “El cuaderno europeo de servicio de interés general y los servicios municipales",
Cuadernos de Derecho Local, no32, págs. 110-111.

SARASA, S.; y SALES, A. (2009): Itinerarios y factores de exclusión social, Ayuntamiento de Barcelona; Universitat Pompeu Fabra; y Fundación La Caixa.

UNIÓN EUROPEA (2014): “Directiva 2014/24/UE del Parlamento Europeo y del Consejo, de 26 de febrero de 2014, sobre contratación pública y por la que se deroga la Directiva 2004/18/CE", Diario Oficial de la Unión Europea, L94, 28-314, págs. 65-242 [khttp://eur-lex.europa.eu/ legal-content/ES/TXT/?qid=1509987983112\&ur $\mathrm{i}=$ CELEX:32014Lo024

VV.AA. (2016): Guía para la Aplicación de la Ley 31/2015. Impacto de la declaración de las Empresas de Inserción como entidades prestadoras de Servicios de Interés Económico General, Madrid, Federación de Asociaciones Empresariales de Empresas de Inserción [<http://www.faedei.org/images/docs/ document065.pdf>]. 